\title{
Aportes
}

\section{Psicología cognitiva e inteligencia artificial}

\author{
Maria Virginia Arango $T$. \\ Estudiante X Semestre \\ (Curso Impacto social de la computadora). \\ Facultad de Ingeniería de Sistemas.
}

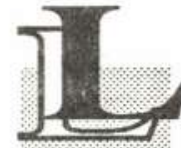

a inteligencia artificial se encarga del estudio de las facultades mentales usando modelos computacionales. Su objeto es ánfora simular el conocimiento humano, simular el procesamiento de información que se lleva a cabo en el cerebro.

Aquí podemos ver la influencia que ha tenido la teoría del conocimiento y la psicología cognitiva en la inteligencia artificial. Según el constructivismoel ser humano nace con cierta herencia, con ciertos datos que hacen parte del conocimiento inicial que el individuo tiene, con el tiempo y por medio de la experiencia estos datos de alguna forma se van aumentando y por ende se aumenta su conocimiento. Todos estos procesos se llevan a cabo en el cerebro. Esto es lo que los expertos en inteligencia artificial han querido realizar dotando a la máquina de cierto conocimiento y de procesos inferenciales de tipo heurístico que se encarguen de producir nuevos hechos o nuevos conocimientos.

La inteligencia artificial partiendo de esto e influenciada por la teoría del conocimiento y la psicología cognitiva quiere simular estos procesos tan complejos que se llevan a cabo en el cerebro, usando el computador. Para esto secrean o tratan de crear sistemas inteligentes * que, al ser dotados con un conocimiento inicial (o base del conocimiento, como serían los datos iniciales con que nace el individuo según la teoría del constructivismo) y a la vez interactúan con el usuario, pueden ir adquiriendo conocimiento o sea, aprendiendo con la experiencia a través del tiempo.

El problema radica en que es muy complejo tratar de representar el conocimiento y la manera como éste se va aumentando. Un sistema inteligente que aprenda de la experiencia obtenida al interactuar con el usario tendría que ser muy grande y con mucha capacidad, para poder almacenar el conocimiento. En mi concepto, el conocimiento que tiene el ser humano es infinito, ya que día a día se aprende más y siempre hay más cosas para conocer; mientras que la máquina es

\footnotetext{
*Un sistema inteligente es un sistema que usa conocimiento común o de dominio público y profundo, y procesos inferenciales de tipo heurístico para la solución de problemaso generación de nuevos hechos o conocimiento.
} 
limitada, su capacidad de almacenamiento no puede crecer a medida que aumenta su base del conocimiento, siempre va a llegar a un límite. Por lo tanto, sería imposible almacenar tanto conocimiento.

Es tan amplioel conocimiento que manejamos los seres humanos que como dice Chomsky en $\& L a$ Ciencia Cognitiva como Disciplina Unificada» : «Las capacidades cognoscitivas de los humanos y la capacidad linguística en particular solo pueden explicarse si aceptamos que los individuos tienen ciertas estructuras innatas, cierto conocimiento a priori, que constituyen la base a partir de la cual se funda todo aprendizaje posterior».. Esto es lo que trata de hacer o de simular la inteligencia artificial dotando sus sistemas inteligentes de una base de conocimiento. Pero, el gran interrogante siempre ha sido y seguirá siendo, estos sistemas soncapaces de aprender a partir de la experiencia que tienen al estar en contacto con el usuario? Podrán aprender de sus errores, como hace el ser humano, que aprende de la experiencia, de los errores que comete?. Hay algo muy importante en el ser humano y es la capacidad de traer a la mente imágenes y recordar, así como la capacidad de asociar las cosas con el fin de producir conocimiento de una forma distinta y esto no lo puede hacer una máquina.

Por otra parte, la inteligencia artificial ha influenciado la teoría del conocimiento en el sentido de que al querer simular la mente humana, se ha traído de nuevo a colación un tema tan viejo, como es la teoría del conocimiento. El nuevo fenómeno tecnológico nos ha hecho reflexionar sobre algo tan complejo como es el conocimiento humano. Puede el conocimiento humano ser representado o simulado en una máquina que, de cierta forma, es un tanto limitada?

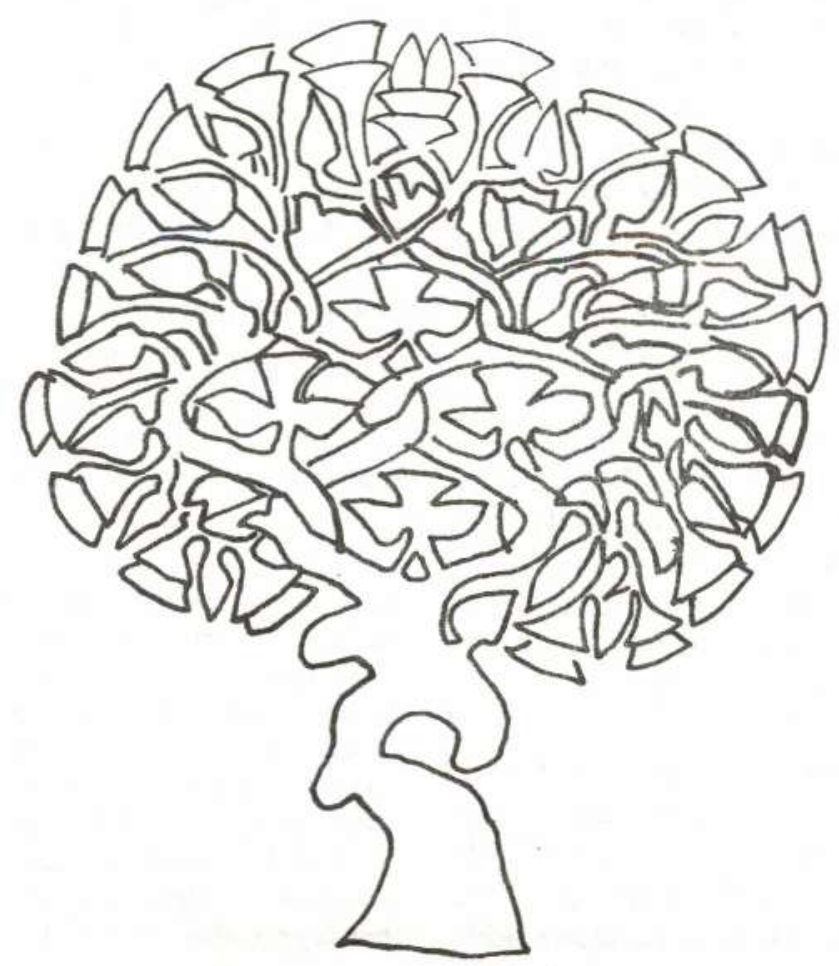

